\title{
Advanced drug delivery to the lymphatic system: lipid-based nanoformulations
}

This article was published in the following Dove Press journal:

International Journal of Nanomedicine

25 July 2013

Number of times this article has been viewed

\section{Arshad Ali Khan \\ Jahanzeb Mudassir \\ Noratiqah Mohtar \\ Yusrida Darwis}

School of Pharmaceutical Sciences, Universiti Sains Malaysia, Minden,

Penang, Malaysia
Correspondence: Yusrida Darwis School of Pharmaceutical Sciences, Universiti Sains Malaysia, Minden, I 1800 Penang, Malaysia

Tel +60 46534588

Fax +6046570017

Email yusrida@usm.my
Abstract: The delivery of drugs and bioactive compounds via the lymphatic system is complex and dependent on the physiological uniqueness of the system. The lymphatic route plays an important role in transporting extracellular fluid to maintain homeostasis and in transferring immune cells to injury sites, and is able to avoid first-pass metabolism, thus acting as a bypass route for compounds with lower bioavailability, ie, those undergoing more hepatic metabolism. The lymphatic route also provides an option for the delivery of therapeutic molecules, such as drugs to treat cancer and human immunodeficiency virus, which can travel through the lymphatic system. Lymphatic imaging is useful in evaluating disease states and treatment plans for progressive diseases of the lymph system. Novel lipid-based nanoformulations, such as solid lipid nanoparticles and nanostructured lipid carriers, have unique characteristics that make them promising candidates for lymphatic delivery. These formulations are superior to colloidal carrier systems because they have controlled release properties and provide better chemical stability for drug molecules. However, multiple factors regulate the lymphatic delivery of drugs. Prior to lymphatic uptake, lipid-based nanoformulations are required to undergo interstitial hindrance that modulates drug delivery. Therefore, uptake and distribution of lipidbased nanoformulations by the lymphatic system depends on factors such as particle size, surface charge, molecular weight, and hydrophobicity. Types of lipid and concentration of the emulsifier are also important factors affecting drug delivery via the lymphatic system. All of these factors can cause changes in intermolecular interactions between the lipid nanoparticle matrix and the incorporated drug, which in turn affects uptake of drug into the lymphatic system. Two lipid-based nanoformulations, ie, solid lipid nanoparticles and nanostructured lipid carriers, have been administered via multiple routes (subcutaneous, pulmonary, and intestinal) for targeting of the lymphatic system. This paper provides a detailed review of novel lipid-based nanoformulations and their lymphatic delivery via different routes, as well as the in vivo and in vitro models used to study drug transport in the lymphatic system. Physicochemical properties that influence lymphatic delivery as well as the advantages of lipid-based nanoformulations for lymphatic delivery are also discussed.

Keywords: lymphatic system, blood circulation, solid lipid nanoparticles, nanostructured lipid carriers

\section{Introduction}

Over the past 25 years, vascular research has primarily focused on the biology of blood rather than the biology of lymph because of the difficulties involved in visualizing the lymphatic system and a lack of appreciation of its distinctive function. Currently, the lymphatic system is gaining more interest and achieving more recognition outside of cancer biology. 
The lymphatic system is part of the circulatory system and is comprised of an intricate network of conduits that carry a clear fluid called lymph. The primary functions of the lymphatic system are to maintain the body's water balance by returning extracellular fluid that has leaked out into the interstitial space back to the systemic circulation and to transport immune cells to the lymph nodes. ${ }^{1,2}$ Further, the lymphatic system has specialized roles in specific areas because of its nonuniform structure and function throughout the body. It plays an essential role in absorption of longchain fatty acids, triglycerides, cholesterol esters, lipid soluble vitamins, and xenobiotics., ${ }^{2,3}$ Drug delivery via the lymphatic system has several major advantages, including circumventing first-pass metabolism in the liver and targeting drugs to diseases that spread through the lymphatic system (eg, certain types of cancer and human immunodeficiency virus). The lymphatic system also plays an active role in disseminating metastatic cancer cells and infectious agents throughout the body. Cancer cells use the lymph nodes as a reservoir to spread to other areas of the body. ${ }^{2,4-7}$

There are three ways to deliver drugs through the intestinal lymphatic vessels. ${ }^{8} 9$ First, lymphatic capillaries are comprised of single-layered, nonfenestrated endothelial cells. These cells are arranged in a highly gapped and overlapped manner to form a porous wall in the lymphatic vasculature, which allows for macromolecular targeting to the lymphatic system. ${ }^{3}$ Therefore, increased absorption of hydrophilic macromolecules and macroconjugates is possible by opening up the paracellular route with the help of an absorption enhancer. ${ }^{10}$ Secondly, gut-associated lymphoid tissue consists of either isolated or aggregated lymphoid follicles that form Peyer's patches, which provide an entry point for drug to the lymphatics (Figure 1A). ${ }^{11-14}$ Finally, the primary route for lipid transport is through the intestinal walls via transcellular absorption, paracellular transport, P-glycoprotein, and cytochrome P450 inhibition. Increased production of chylomicrons is associated with delivery of lipophilic compounds into the lymphatic system (Figure 1B). ${ }^{9}$ Utilization of this route is discussed in this review in terms of lymphatic targeting of lipid-based nanoformulations.

A number of lipid-based formulations, including emulsions, micellar systems, self-emulsifying drug delivery systems, self-microemulsifying drug delivery systems, self-nanoemulsifying drug delivery systems, liposomes, solid lipid nanoparticles (SLNs), and nanostructured lipid carriers (NLCs) have been investigated as drug carriers for the lymphatic system (Table 1). ${ }^{15-46}$
Some therapeutic agents have also been incorporated into polymer-based lipid nanoparticles to improve lymphatic drug delivery. Using this approach, the anatomy of the lymphatic system determines delivery of the therapeutic agent, ie, the architecture of the endothelial wall of the lymphatic vessel provides the open space necessary to facilitate delivery of a complex of high molecular weight drug polymers. These studies were conducted using anticancer molecules to potentiate lymphatic delivery. A number of natural (dextran and hyaluronic acid) and synthetic (polyhexylcyanoacrylate, polymethylmethacrylate, poly[L-lactic acid], and poly[lacticco-glycolic acid]) polymers have been used as carriers to deliver drugs through the lymphatic system. ${ }^{47-54}$

The lymphatic system was previously thought to play a passive role in the spread of disease throughout the body; however, recent findings have opened up a new chapter regarding the role of the lymphatic system in the metastasis of cancer. The discovery of specific markers and growth factors in the lymphatic endothelium, such as vascular endothelial growth factor (VEGF)-C, VEGF-D, and VEGF-A, the VEGF-D receptor (VEGFR-3), and Prox-1, have provided the opportunity for specific drug targeting to diminish lymphangiogenesis and metastasis in the lymphatic system. ${ }^{55}$

In the development of drug delivery to target progressive lymphatic disease, such as human malignancy, lymphatic imaging techniques play a crucial role in planning treatment. The disease invades the lymphatic system in the first stage of progression during metastasis. Lymphatic imaging techniques can be used to evaluate both the disease state and the effectiveness of drug therapy. Imaging techniques using visible dyes and radionuclides do not produce clear images; however, new techniques such as fluorescence imaging, magnetic resonance imaging, quantum dots, and nanocarriers have been shown to have greater sensitivity and higher resolution, while eliminating unnecessary biopsies or removal of healthy nodal tissue..$^{56-59}$

\section{Lipid-based nanoparticles}

Lipid-based nanoparticles containing a solid matrix are generally divided into two groups, ie, SLNs and NLCs. In the early 1990s, SLNs were identified as an alternative to colloidal drug carriers, such as liposomes, microemulsions, nanoemulsions, and nanocapsules. ${ }^{60}$ Both SLNs and NLCs have many advantages compared with other colloidal carrier systems, including controlled drug release and improved chemical stability of drug molecules. Moreover, these carrier systems can also be produced on a large scale. ${ }^{61-63}$ 
A
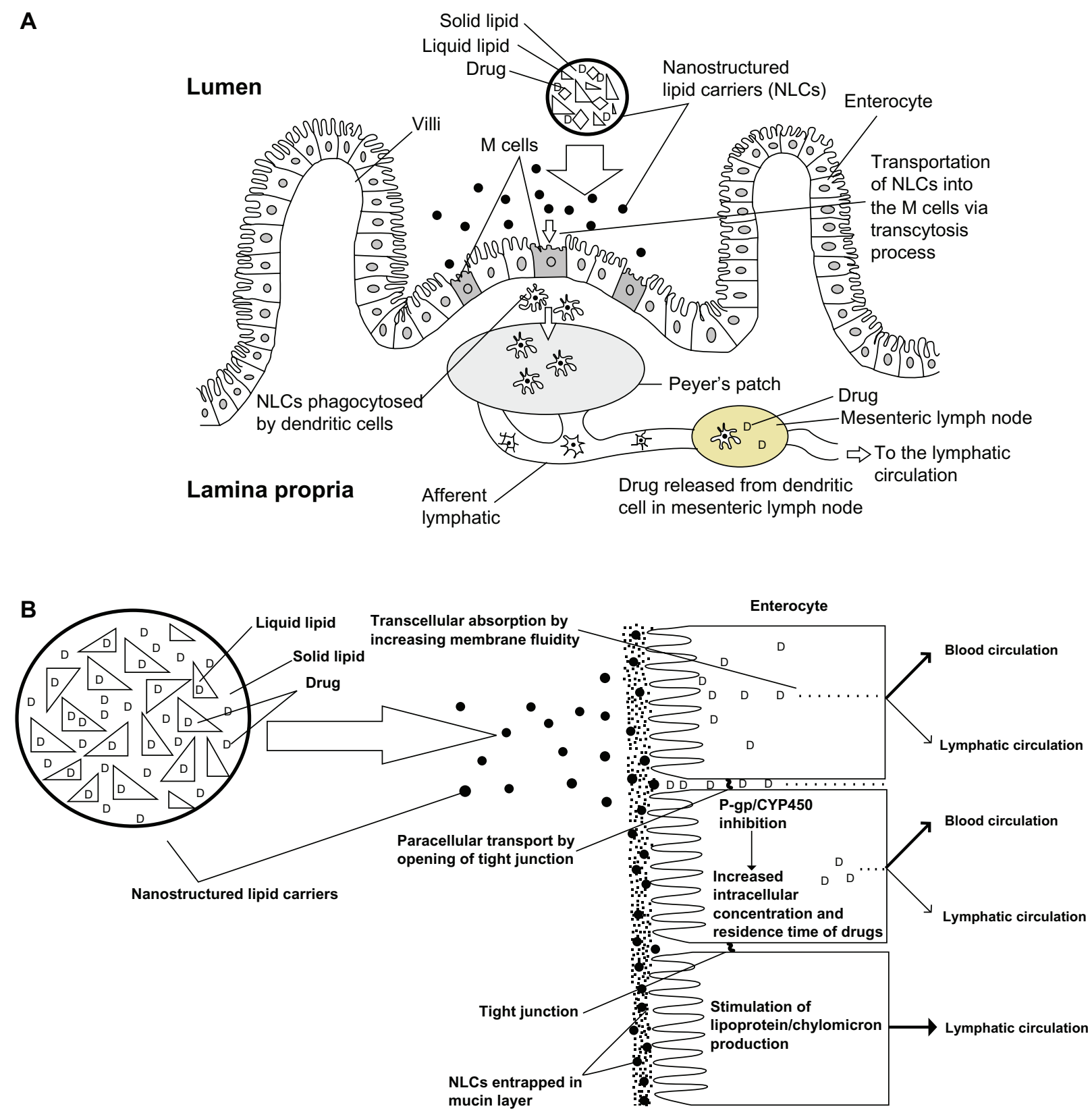

Enterocyte

Figure I (A) Schematic transverse section of Peyer's patch, illustrating M cell transportation of lipid based formulation (nanostructured lipid carriers) to the lymphatic vessels. (B) Schematic diagram of the different mechanisms of the intestinal transport of lipid based formulation (nanostructured lipid carriers) through blood and lymphatic circulation. Abbreviations: P-gp, P-glycoprotein; CYP450, cytochrome P450 enzyme; M cell, membranous cell.

\section{Solid lipid nanoparticles}

SLNs offer a prominent advantage over other nanoparticulate systems because they use physiological lipids and surfactants, which are generally recognized as safe. The commonly used lipids in the SLNs preparation are fatty acids, waxes, monoglycerides, diglycerides, and triglycerides; surfactants such as poloxamer and polysorbate are also widely used. Further, the possibility of avoiding a solvent using high-pressure homogenization can help avoid the carrier biotoxicity problem in humans. ${ }^{64,65}$ SLNs involve formation of a relatively rigid core consisting of lipids that are solid at room temperature. Thus, SLNs can help improve stability and provide controlled release and drug targeting. ${ }^{66}$ The minute size of this formulation enables efficient uptake of drugs into the intestine, particularly via the lymphatic route, involving particles only $20-500 \mathrm{~nm}$ in diameter. ${ }^{67}$

Absorption via the lymphatic route can be used for delivery of cytotoxic agents to overcome the limitations of nonspecificity, drug resistance, and severe toxicity ${ }^{68}$ Several cytotoxic drugs have been incorporated into SLNs, including 
Table I Formulations that have been used for lymphatic targeting

\begin{tabular}{|c|c|c|}
\hline Formulations & Drugs & References \\
\hline Emulsion & Penclomedine & 15 \\
\hline Emulsion & Ontazolast & 16 \\
\hline Microemulsion & Puerarin & 17 \\
\hline Microemulsion & Raloxifene & 18 \\
\hline Micellar systems & Cyclosporin A & 19 \\
\hline SEEDS & Coenzyme QI0 & 20 \\
\hline SMEDDS & Halofantrine & 21 \\
\hline SMEDDS & Nobiletin & 22 \\
\hline SMEDDS & Valsartan & 23 \\
\hline SMEDDS & Vinpocetine & 24 \\
\hline SMEDDS & Silymarin & 25 \\
\hline SMEDDS & Sirolimus & 26 \\
\hline SNEDDS & Carvedilol & 27 \\
\hline SNEDDS & Valsartan & 28 \\
\hline SNEDDS & Halofantrine & 29 \\
\hline Liposomes & $\operatorname{lgGI}$ & 30 \\
\hline Liposomes & Doxorubicin & $31-33$ \\
\hline Liposomes & Cefotaxime & 34 \\
\hline Liposomes & 9-nitro-camptothecin & 35 \\
\hline Liposomes & Paclitaxel & 36 \\
\hline Liposomes & Ovalbumin & 37 \\
\hline SLNs & Etoposide & 38 \\
\hline SLNs & Methotrexate & 39 \\
\hline SLNs & Idarubicin & 40 \\
\hline SLNs & Tobramycin & $4 I, 42$ \\
\hline SLNs & Nimodipine & 43 \\
\hline NLCs & Testosterone & 44 \\
\hline NLCs & Vinpocetine & 45 \\
\hline NLCs & Tripterine & 46 \\
\hline
\end{tabular}

Abbreviations: SEEDS, self-emulsifying drug delivery systems; SMEDDS, selfmicroemulsifying drug delivery systems; SNEDDS, self-nanoemulsifying drug delivery systems; SLNs, solid lipid nanoparticles; NLCs, nanostructured lipid carriers.

idarubicin, methotrexate, and etoposide. ${ }^{38-40,69}$ However, conventional intravenous administration of cytotoxic drugs has limited tumor uptake because of minimal access to the tumor, decreased circulation time due to faster clearance by the phagocytic system, and decreased targeting..$^{70}$ Therefore, alternative routes of administration have been explored for SLNs, including the subcutaneous, pulmonary, and duodenal routes. ${ }^{38-42,69,71-73}$

\section{Subcutaneous route for lymphatic delivery of SLNs}

A study comparing the various routes of administration for etoposide-loaded tripalmitin (ETPL) in SLNs was performed by Harivardhan et al in mice bearing Dalton's lymphoma. ${ }^{38}$ This study compared the biodistribution of radiolabeled free etoposide and radiolabeled ETPL nanoparticles via three different administration routes, ie, intravenous, subcutaneous, and intraperitoneal. Etoposide and ETPL nanoparticles were labeled using ${ }^{99 \mathrm{~m}} \mathrm{Tc}$ (Technetium) and detected using a gamma ray spectrometer and gamma scintigraphy. Subcutaneous administration showed superior tumor uptake at 24 hours compared with both intraperitoneal and intravenous administration, with 8-fold higher drug uptake than intraperitoneal and 59-fold higher drug uptake than intravenous routes. Subcutaneous administration also showed a significant reduction in drug uptake by organs of the reticuloendothelial system (ie, lung, liver, and spleen), which resulted in longer circulation of ETPL nanoparticles. This route also had a relatively low tissue distribution, which can reduce the systemic side effects of etoposide. Initial uptake of ETPL nanoparticles by the tumor after subcutaneous administration was low, but increased over time. This slow deposition of ETPL nanoparticles suggests the possibility for controlled release therapy. Thus, subcutaneous injection of drug adjacent to the tumor site could be a better route for chemotherapeutic treatment of lymphatic-related tumors than intravenous or intraperitoneal administration. ${ }^{38}$

\section{Pulmonary route for lymphatic delivery of SLNs}

Targeted delivery of SLNs via the pulmonary route has significant potential in certain types of cancer. Some solid endocrine tumors, such as small cell lung carcinoma, show high levels of metastatic proliferation. These tumors spread initially through one hemithorax and its regional lymph nodes, eventually travelling through the lymphatic system to the blood circulation. ${ }^{7-77}$ This type of cancer metastasis relies on drainage from the lymph nodes. ${ }^{74,76}$ Further, alveolar clearance of drug particles up to a certain diameter (200 nm) involves the lymphatic system. ${ }^{71,78,79}$ This renders drug targeting with SLNs feasible, and several studies have been done involving delivery of SLNs in patients with lung cancer via nebulization and gene therapy. ${ }^{72,80}$

Videira et al formulated an SLNs system incorporating paclitaxel, which is widely used in the treatment of non-small cell lung cancer. ${ }^{72}$ In that study, nebulization of paclitaxel-loaded SLNs was compared with intravenous administration of paclitaxel alone using a conventional formulation in mice inoculated with MXT-B2 cells to develop lung metastases. Treatment with paclitaxelloaded SLNs demonstrated a significant 20-fold reduction in inhibitory concentration of $50 \%$ of cell growth $\left(\mathrm{IC}_{50}\right)$ values and a $19.43 \%$ reduction in cell viability compared with intravenous administration of paclitaxel alone. Unlike intravenous paclitaxel, the SLNs formulation showed an absence of toxicity with prolonged treatment, 
suggesting that SLNs delivery has high selectivity and low systemic circulation. Uptake of SLNs into the lymphatic system was demonstrated earlier by Videira et al using radiolabeled SLNs whereas other researchers used a computed tomography contrast agent. ${ }^{71,79}$ Both studies demonstrated that biodistribution of SLNs occurs primarily via the lymphatic system rather than by the blood circulation. Thus, specific delivery of cytotoxic drugs via inhalation using SLNs could be a promising option for chemotherapy in the future.

\section{Intestinal route for lymphatic delivery of SLNs}

The gastrointestinal tract is the preferred route for drug delivery. However, because of its unique anatomy and physiology, several factors may affect drug bioavailability, including the drug's solubility in the gastrointestinal tract, the $\mathrm{pH}$ in the tract, and the amount of time spent there. ${ }^{73}$ This route also subjects drugs to presystemic hepatic metabolism, which can reduce drug bioavailability. To overcome this, the lymphatic absorption of SLNs can be exploited by incorporating drugs into SLNs to circumvent first-pass metabolism. Several groups of researchers have explored this and reported increased bioavailability when SLNs incorporating drugs are administered intraduodenally. ${ }^{39-41}$

The superior uptake of methotrexate through the lymphatic system and into the systemic circulation has been demonstrated in methotrexate-loaded SLNs. ${ }^{39}$ In this study, the effect of different types of lipid-based SLNs was investigated using stearic acid, monostearin, tristearin, and Compritol ${ }^{\circledR} 888$ ATO. Intraduodenal administration of methotrexate-loaded SLNs showed increased bioavailability of methotrexate regardless of the types of lipid used, with the greatest increase observed in SLNs containing Compritol 888 ATO compared with the methotrexate solution. A 10-fold increase in methotrexate concentration was observed in the lymphatic system with methotrexate-loaded SLNs compared with the methotrexate solution.

Another study incorporated idarubicin into SLNs and compared this with an idarubicin solution for intraduodenal and intravenous administration. ${ }^{40}$ Duodenal administration of idarubicin-loaded SLNs enhanced drug bioavailability, as indicated by a 21 -fold increase in the area under the curve compared with the idarubicin solution. This study also showed less distribution of idarubicin to the heart, lung, spleen, and kidneys, which may reduce the cardiotoxicity of idarubicin. Because the elimination half-life of idarubicin-loaded SLNs was increased by 30 -fold compared with idarubicin solution, it was suggested that SLNs could be useful as a prolongedrelease system. The study also showed a higher area under the curve when idarubicin-loaded SLNs were administered intraduodenally compared with intravenous administration of the same formulation. These findings show that drugs formulated with SLNs can provide specific targeted drug delivery to increase clinical efficacy and reduce the toxicity of oral anticancer agents. ${ }^{40}$

\section{Nanostructured lipid carriers}

The lipid-based NLCs system was developed to overcome the limitations of SLNs, such as drug loading into a solid matrix and drug expulsion during storage because of polymorphic modification of the lipid particles. SLNs use only one form of lipid, ie, a solid lipid that orients the drug between the fatty acid chains of glycerides. In contrast, NLCs use a blend of both solid and liquid lipids to form a controlled nanostructure. Imperfections between the lipids provide spaces to accommodate the drugs in the matrix, resulting in maximum drug-loading capacity. ${ }^{81,82}$ Further, NLCs are less susceptible than SLNs to gelation during both preparation and storage. ${ }^{81,83}$ Thus, NLCs are considered to represent a second generation of lipid nanoparticle formulations. ${ }^{81}$

\section{Subcutaneous route for lymphatic delivery of NLCs}

The subcutaneous route is an attractive one for lymphatic delivery of lipid nanoparticles, with several advantages, including drug accumulation at the site of administration for a longer period of time, low clearance, sustained release, and increased absorption. On subcutaneous administration, lipid nanoparticles are not directly transported into the bloodstream because capillaries control the permeability of water and small molecules. Instead, the lymphatic capillaries surrounding the subcutaneous injection site absorb the lipid-based nanoparticles. Absorption of these lipid-based nanoparticles into the lymphatic system depends primarily on the size of the nanoparticles. Larger lipid nanoparticles accumulate at the injection site, and the drug is slowly released from the nanoparticles. The free drug can enter the blood circulation via pores on the walls of the capillaries. Smaller lipid nanoparticles $(<0.1 \mu \mathrm{m})$ can easily access the lymphatic capillaries and concentrate in regional lymph nodes. ${ }^{84}$ Thus, based on these advantages, NLCs could be developed as a carrier for lymphatic drug delivery by subcutaneous administration because they have improved physicochemical properties compared with other lipid-based nanocarrier systems. 


\section{Pulmonary route for lymphatic delivery of NLCs}

Drug administration via the pulmonary route has several advantages compared with the oral and parenteral routes. The pulmonary route avoids first-pass metabolism, reduces systemic toxicity, is noninvasive, minimizes the need for continuous dosing, allows the drugs administered to reach less accessible parts of the lung directly, and enables increased local concentrations of drug. ${ }^{85}$ The pulmonary route shows great potential for the delivery of NLCs into the lymphatic circulation. The particle size of NLCs can be reduced to less than $500 \mathrm{~nm}$, which could increase drug deposition in the lung epithelium because of their diffusional mobility ${ }^{86}$ NLCs are lipid-based nanoparticles that could be used as a carrier for targeting drugs to small cell lung cancer and human immunodeficiency virus, both of which spread through the lymphatic system and can cross into the systemic circulation. ${ }^{4-7,87}$ Thus, NLCs have the potential to provide a drug delivery mechanism via the lymphatic system through the pulmonary route and may have increased effectiveness compared with SLNs.

\section{Intestinal route for lymphatic delivery of NLCs}

NLCs have the potential to be an effective method for oral drug delivery, because they can increase solubility and enhance the oral bioavailability of drugs that are either hydrophobic or poorly soluble in water. ${ }^{88}$ Among the traditional lipid-based formulations, NLCs have become an important alternative to the more traditional colloidal drug carriers. ${ }^{81}$ Zhuang et al developed drug-loaded NLCs to improve the oral bioavailability of vinpocetine.$^{45}$ Both vinpocetine-loaded NLCs and a vinpocetine suspension were orally administered to male Wistar rats. The time taken to reach maximum plasma concentrations $\left(\mathrm{T}_{\text {max }}\right)$ and the peak concentration reached $\left(\mathrm{C}_{\max }\right)$ for the vinpocetine suspension were 30 minutes and $354.29 \pm 57.49 \mathrm{ng} / \mathrm{mL}$, respectively, whereas the $\mathrm{T}_{\text {max }}$ and $\mathrm{C}_{\text {max }}$ of vinpocetine-loaded NLCs were 1.5 hours and $679.29 \pm 135.57 \mathrm{ng} / \mathrm{mL}$, respectively. The $\mathrm{T}_{\max }$ for vinpocetine-loaded NLCs was one hour longer than for the vinpocetine suspension, indicating indirect transport of NLCs into the systemic circulation. The $\mathrm{C}_{\max }$ for vinpocetineloaded NLCs was also significantly higher than for the vinpocetine suspension. The area under the curve for the vinpocetine-loaded NLCs was 3.2-fold greater than that of the vinpocetine suspension. In vivo pharmacokinetic analysis showed a $322 \%$ increase in the relative bioavailability of vinpocetine-loaded NLCs compared with the vinpocetine suspension after oral administration. These results suggest that NLCs can improve the oral bioavailability of drugs which are poorly soluble in water. ${ }^{45}$ One possible reason for the enhanced bioavailability of vinpocetine could be that NLCs are transported in the lymphatic system, so largely avoid first-pass metabolism, which is the main cause for the low bioavailability of vinpocetine. ${ }^{89,90}$

In another study, Zhou et al developed tripterine NLCs and evaluated their potential as an oral drug delivery system. ${ }^{46}$ A rat intestinal perfusion model was used to compare the absorption of tripterine-loaded NLCs with that of a tripterine solution. The effective permeability of tripterine NLCs in the duodenum, jejunum, ileum, and colon was 2.1, 2.7, 1.1, and 1.2 times higher, respectively, compared with the tripterine solution. The percentage absorption of tripterineloaded NLCs in $10 \mathrm{~cm}$ of duodenum, jejunum, ileum, and colon was 2.2, 2.3, 1.2, and 1.3 times greater, respectively, than for the tripterine solution. ${ }^{46}$ These results indicate that NLCs could be used as a carrier to improve the absorption of tripterine in the gastrointestinal tract.

\section{Models used to study drug transport in the lymphatic system In vivo models}

In the in vivo model, cannulation of the mesenteric or thoracic lymphatic ducts is performed in animals to investigate drug transport in the intestinal lymphatic system. ${ }^{91}$ This model allows for direct measurement of drug concentrations in lymph. Because it is an irreversible and invasive surgical process, the procedure cannot be performed on humans. ${ }^{92}$ Small animals, such as rats, are commonly used, but some larger animals, including sheep, pigs, rabbits, and dogs, have also been used for this model. ${ }^{92-100}$

Another in vivo model is the lymphatic venous shunt, in which drug concentrations in lymph are measured at fixed time intervals, and lymph is collected over a longer period of time. Further, an indirect method has been used in an oral bioavailability study to evaluate intestinal lymphatic drug transport in both the presence and absence of inhibitors of intestinal chylomicron flow. This method has the advantage of not requiring a surgical procedure, as does the lymphatic duct cannulation model. ${ }^{101-104}$

\section{In vitro models}

Various in vitro models can serve as an alternative to in vivo models for studying lymphatic drug transport. In the intestinal permeability model, Caco-2 cells are used to evaluate intracellular lipoprotein-lipid assembly 
and to examine the effect of lipids and lipidic excipients on incorporation of drug with lipoproteins in lymphatic transport. ${ }^{88,105-107}$ In one in vitro model, Gershkovich and Hoffman described a correlation between the degree of ex vivo incorporation of a drug into chylomicrons and the extent of intestinal lymphatic drug transport. ${ }^{108}$ According to a lipolysis model described by Dahan and Hoffman, in vivo drug absorption could be predicted by evaluating drug release from a lipid-based drug delivery system and estimating precipitation of the drug during lipolysis. ${ }^{109}$ Holm and Hoest reported an in silico method that established a quantitative relationship between the molecular structure and amount of drug transferred from the intestinal to the lymphatic system. ${ }^{102-104,110}$

\section{Factors affecting transport of nanoparticles to the lymphatic system}

Gastrointestinal labile molecules such as anticancer, anti-HIV and immunosuppressant compounds have been incorporated into lipid-based nanocarriers. The uptake and distribution of the lipid-based nanocarriers through the gastrointestinal epithelium to the peripheral lymphatic duct have been explored. ${ }^{111-113}$ Some groups have reported that uptake of lipid-based nanoparticles by the lymphatic system and their distribution in the lymphatic circulation is dependent on route of administration. Moreover, other factors such as size, surface charge, molecular weight, hydrophobicity, types of lipid, and concentration of the emulsifier used have also been observed to influence the uptake and distribution of lipidbased nanoparticles in the lymphatic circulation. . $2,39,53,69$

\section{Size of nanoparticles}

The size and composition of nanoparticles play an important role in lymphatic uptake and particle retention in lymph nodes. Carriers such as colloidal and lipid particles show more efficiency in lymphatic uptake. Several drug molecules, including anticancer and monoclonal antibodies, have been incorporated into dendrimers and lipid-based nanoparticles, such as liposomes, SLNs, and NLCs, on the basis of their size and the nature of the preparations for lymphatic targeting. ${ }^{38,114}$ Oussoren et al reported that a particle size of 10-100 nm is optimal for lymphatic uptake via subcutaneous administration. ${ }^{115}$ A particle size smaller than $10 \mathrm{~nm}$ is absorbed via the systemic circulation, whereas a particle larger than $100 \mathrm{~nm}$ shows preferential uptake via the lymphatic system but at a slower rate. However, particles larger than $100 \mathrm{~nm}$ have not been clearly defined.
Further, the authors observed that interstitial injection of particles larger than $100 \mathrm{~nm}$ was taken up slowly, and that the particles were trapped at the injection site for a significant period of time.

\section{Surface charge on nanoparticles}

The charge on a drug carrier is also an important factor in lymphatic uptake. Some negatively charged carriers, such as dendrimers, proteins, polylactic-co-glycolic acid nanospheres, and lipid-based nanoparticles (eg, liposomes) have been reported to show higher lymphatic uptake than neutral or positively charged surfaces, which could be due to the fact that the interstitial matrix contains a net negative charge. ${ }^{116-120}$ Therefore, in the interstitium, anionic carrier particles encounter electrostatic repulsion and move more quickly. ${ }^{12,118,121}$ Highly negatively charged particles have been reported to be retained for a longer period of time in the lymph nodes. ${ }^{16,117}$ Conversely, positively charged particles in the interstitium encounter more resistance to move towards the negatively charged interstitium matrix because of the increased electrostatic attraction force. The zeta potential provides information regarding the ionic nature of carrier particles. A zeta potential $<-30 \mathrm{mV}$ indicates a strongly anionic nature, values between +10 and $-10 \mathrm{mV}$ indicate neutral behavior, and values $>+30 \mathrm{mV}$ indicate a cationic nature. ${ }^{122}$

Kaur et al evaluated a zidovudine-loaded liposomes ${ }^{123}$ incorporated with either positively (ie, stearylamine) or negatively (ie, dicetyl phosphate) charge surfactants for lymphatic targeting. Using fluorescent microscopy, the organ distribution and lymphatic uptake of these surface-engineered liposomes was determined, and it was reported that the negatively charged liposomes showed improved lymphatic uptake compared with the positively charged liposomes. Another study by Patel et al observed the order of liposomal uptake by the lymph nodes to be as follows: negative $>$ positive $>$ neutral charge. ${ }^{117}$

\section{Molecular weight of drugs}

Lymphatic drug delivery via the subcutaneous route shows a linear relationship between molecular weight and extent of absorption of macromolecules. Increasing the molecular weight causes a decrease in uptake of molecules by the capillaries and increased uptake into the lymphatic system at the injection site. Molecules weighing less than $1000 \mathrm{Da}$ are easily absorbed by the capillaries before they are taken into the lymphatic circulation. In contrast, molecules weighing more than $16,000 \mathrm{Da}$ tend to be absorbed by the lymphatic system rather than by the capillaries. ${ }^{12}$ 


\section{Hydrophobicity of nanoparticles}

Hawley et al showed that hydrophobicity plays an important role in facilitating lymphatic uptake of lipid-based nanoformulations from the administration site. ${ }^{12}$ The hydrophobicity of the particles can be correlated with their surface properties, and is mainly responsible for phagocytosis and lymphatic uptake. Dahlback et al demonstrated that decreasing the hydrophobicity of bacteria would decrease phagocytosis. ${ }^{124}$ The increased opsonization could be because opsonins attach more easily to hydrophobic surfaces than to hydrophilic surfaces. Because of this phenomenon, phagocytosis would increase, thus increasing lymphatic uptake. ${ }^{125}$

\section{Lipid solubility and partition coefficient of drugs}

Lipid solubility and the partition coefficient are essential physicochemical properties of drugs, and have a major role in lymphatic drug transport. For example, Charman and Stella reported that triglyceride solubility and the $\log P$ value of a drug should be $>50 \mathrm{mg} / \mathrm{mL}$ and $>5$, respectively, for effective lymphatic transport. ${ }^{126}$ They compared the lymphatic transport of dichlorodiphenyltrichloroethane and hexachlorobenzene, which have $\log P$ values of 6.19 and 6.53, respectively. Although the $\log P$ values of both drugs were similar, the drugs were dissimilar in their triglyceride solubility, with dichlorodiphenyltrichloroethane having a 13-fold higher triglyceride solubility than hexachlorobenzene. Their transport results showed that dichlorodiphenyltrichloroethane had higher lymphatic uptake $(33.5 \%)$ than hexachlorobenzene $(2.3 \%)$. These authors concluded that the difference in lymphatic transport could be due to the difference in triglyceride solubility between the two drugs. However, Myers and Stella observed in their study that higher $\log P$ values and increased lipid solubility did not always result in significant lymphatic uptake. ${ }^{15}$ Penclomedine has poor lymphatic transport (only about $3 \%$ of the dose administered is transported) despite its $\log P$ value of 5.48 and lipid solubility of $175 \mathrm{mg} / \mathrm{mL}$. Reduced lymphatic transport of penclomedine could be due to the stronger affinity of this drug for red blood cells and plasma proteins than for chylomicrons. Thus, higher concentrations of penclomedine have been detected in the blood circulation than in the lymphatic circulation. ${ }^{15}$

\section{Types of lipids used in nanoparticles}

Lipid-based nanoformulations are essentially composed of triglycerides which arrange themselves in such a way that the polar head is exposed to the aqueous phase. This arrangement is similar to that of chylomicrons. The composition of lipids in lipid-based nanoformulations may influence their absorption through the transcellular route via polar intestinal epithelial cells. Paliwal et al prepared methotrexate-loaded SLNs and evaluated the effect of lipids on the characteristics of the formulation. ${ }^{39}$ These authors prepared methotrexate-loaded SLNs using the solvent diffusion method with four different types of lipids, ie, Compritol 888 ATO, tristearin, stearic acid, and monostearin. The studied formulations were compared for their size, charge, morphology, drug entrapment, in vitro release, and pharmacokinetic properties. The methotrexate-loaded SLNs containing Compritol 888 ATO had the highest entrapment efficiency and the smallest size compared with the other three types of lipid. The advantages of Compritol 888 ATO over the other lipids could be because of the longer chain length of glyceryl behenate, which provides the interchain insertion site for the methotrexate molecule. These authors observed that methotrexate-Compritol 888 ATO SLNs had better bioavailability than the other methotrexate-loaded SLNs formulations studied. This in situ study evaluated lymphatic uptake using cannulation of the mesenteric duct in an anesthetized albino rat model. The lymphatic drug concentration profile showed that the methotrexate-Compritol 888 ATO SLNs formulation had the highest lymphatic uptake compared with the other methotrexate-loaded SLNs formulations ${ }^{39}$ Further, the authors observed a correlation between their in vitro and in situ results.

\section{Concentration of emulsifiers in nanoparticles}

The concentration of the emulsifier directly influences partitioning of a drug in a lipid-based formulation. Thus, it can indirectly affect delivery of the drug in the lipidbased formulation to the target site. Sanjula et al prepared carvedilol SLNs containing 5\%-15\% poloxamer 188 as an emulsifier. ${ }^{127}$ The authors evaluated the effect of various concentrations of poloxamer 188 on entrapment efficiency and lymphatic uptake. They found that increasing the concentration of the emulsifier would decrease the entrapment efficiency. This could be due to the formation of micelles at higher concentrations of poloxamer 188 causing the solubility of carvedilol in the water phase to increase and leading to lower drug entrapment in the SLNs. The in vivo study was performed with four carvedilol SLNs formulations using varying concentrations of poloxamer 188 administered via the intraduodenal route in male Wistar rats. 
Higher area under the concentration-time curve values were measured for the formulation containing the lowest amount of poloxamer 188. The results suggested that higher concentrations of poloxamer 188 would reduce the hydrophobicity of the SLNs and decrease lymphatic uptake of carvedilol, which would result in lower oral bioavailability of the drug. ${ }^{127}$

\section{Conclusion}

Advances in current approaches to lymphatic delivery of lipid-based nanoformulations have been reviewed. The lymphatic route provides new possibilities for delivery of cytotoxic agents and therapeutic molecules with higher first-pass metabolism and lower solubility. This method can serve as a bypass route, especially for anticancer and anti-human immunodeficiency virus drugs, both of which target diseases utilizing the lymphatic system. Drugs that are encapsulated in advanced lipid-based nanoformulations, such as NLCs, are better candidates for lymphatic drug delivery. With appropriate optimization and selection of an effective administration route, lipid-based nanoformulations should have great promise as lymphatic drug delivery systems.

\section{Acknowledgment}

The authors would like to thank the Universiti Sains Malaysia for providing a short-term grant (304/PFarmasi/6312023) to support this work. The authors would also like to thank Miss Safia Akhtar for technical assistance.

\section{Disclosure}

The authors report no conflicts of interest in this work.

\section{References}

1. Miteva DO, Rutkowski JM, Dixon JB, Kilarski W, Shields JD, Swartz MA. Transmural flow modulates cell and fluid transport functions of lymphatic endothelium. Circ Res. 2010;106:920-931.

2. Iqbal J, Hussain MM. Intestinal lipid absorption. Am J Physiol Endocrinol Metab. 2009;296:E1183-E1194.

3. O'Driscol CM. Anatomy and physiology of the lymphatics. In: Charman WN, Stella VJ, editors. Lymphatic Transport of Drugs. Boca Raton, FL: CRC Press Inc; 1992.

4. McCarter MD, Clarke JH, Harken AH. Lymphangiogenesis is pivotal to the trials of a successful cancer metastasis. Surgery. 2004;135: 121-124.

5. Pantel K, Brakenhoff RH. Dissecting the metastatic cascade. Nat Rev Cancer. 2004;4:448-456.

6. Sleeman JP. The lymph node as a bridgehead in the metastatic dissemination of tumors. Recent Results Cancer Res. 2000;157:55-81.

7. Sleeman JP. The relationship between tumors and the lymphatics: what more is there to know. Lymphology. 2006;39:62-68.

8. Muranishi S, Fujita T, Murakami M, Yamamoto A. Potential for lymphatic targeting of peptides. J Control Release. 1997;46:157-164.

9. Porter CJH, Charman WN. Uptake of drugs into the intestinal lymphatics after oral administration. Adv Drug Deliv Rev. 1997;25:71-89.
10. Yoshikawa H, Muranishi S, Kato C, Sezaki H. Bifunctional delivery system for selective transfer of bleomycin into lymphatics via enteral route. Int J Pharm. 1981;8:291-302.

11. Eldridge JH, Hammond CJ, Meulbroeck JA, Staas JK, Gilley RM, Tice TR. Controlled vaccine release in the gut-associated lymphoid tissue. I. Orally administered biodegradable microspheres target the Peyer's patches. J Control Release. 1990;11:205-214.

12. Hawley AE, Davis SS, Illum L. Targeting of colloids to lymph nodes: influence of lymphatic physiology and colloidal characteristics. Adv Drug Deliv Rev. 1995;17:129-148.

13. Beier R, Gebert A. Kinetics of particle uptake in the domes of Peyer's patches. Am J Physiol. 1998;275(1 Pt 1):G130-G137.

14. Wells JM, Mercenier A. Mucosal delivery of therapeutic and prophylactic molecules using lactic acid bacteria. Nat Rev Microbiol. 2008;6: 349-362.

15. Myers RA, Stella VJ. Factors affecting the lymphatic transport of penclomedine (NSC-338720), a lipophilic cytotoxic drug: comparison to DDT and hexachlorobenzene. Int J Pharm. 1992;80: 51-62.

16. Haus DJ, Fogal SE, Ficorilli JV, et al. Lipid-based delivery systems for improving the bioavailability and lymphatic transport of a poorly water-soluble LTB4 inhibitor. J Pharm Sci. 1998;87:164-169.

17. Wu H, Zhou A, Lu C, Wang L. Examination of lymphatic transport of puerarin in unconscious lymph duct-cannulated rats after administration in microemulsion drug delivery systems. Eur J Pharm Sci. 2011;42: 348-353.

18. Thakkar H, Nangesh J, Parmar M, Patel D. Formulation and characterization of lipid-based drug delivery system of raloxifenemicroemulsion and self-microemulsifying drug delivery system. J Pharm Bioallied Sci. 2011;3:442-448.

19. Takada K, Yoshimura H, Shibata N, et al. Effect of administration route on the selective lymphatic delivery of cyclosporin A by lipid surfactant mixed micelles. J Pharmacobiodyn. 1986;9:156-160.

20. Kommuru TR, Gurley B, Khan MA, Reddy IK. Self-emulsifying drug delivery systems (SEDDS) of coenzyme Q10: formulation development and bioavailability assessment. Int J Pharm. 2001;212:233-246.

21. Holm R, Porter CJ, Edwards GA, Müllertz A, Kristensen HG, Charman WN. Examination of oral absorption and lymphatic transport of halofantrine in a triple-cannulated canine model after administration in self-microemulsifying drug delivery systems (SMEDDS) containing structured triglycerides. Eur J Pharm Sci. 2003;20:91-97.

22. Yao J, Lu Y, Zhou JP. Preparation of nobiletin in self-microemulsifying systems and its intestinal permeability in rats. J Pharm Pharm Sci. 2008;11:22-29.

23. Dixit AR, Rajput SJ, Patel SG. Preparation and bioavailability assessment of SMEDDS containing valsartan. AAPS PharmSciTech. 2010;11:314-321.

24. Chen Y, Li G, Wu X, et al. Self-microemulsifying drug delivery system (SMEDDS) of vinpocetine: formulation development and in vivo assessment. Biol Pharm Bull. 2008;31:118-125.

25. Li X, Yuan Q, Huang Y, Zhou Y, Liu Y. Development of silymarin self-microemulsifying drug delivery system with enhanced oral bioavailability. AAPS PharmSciTech. 2010;11:672-678.

26. Sun M, Zhai X, Xue K, et al. Intestinal absorption and intestinal lymphatic transport of sirolimus from self-microemulsifying drug delivery systems assessed using the single-pass intestinal perfusion (SPIP) technique and a chylomicron flow blocking approach: linear correlation with oral bioavailabilities in rats. Eur J Pharm Sci. 2011;43:132-140.

27. Singh B, Khurana L, Bandyopadhyay S, Kapil R, Katare OO. Development of optimized self-nano-emulsifying drug delivery systems (SNEDDS) of carvedilol with enhanced bioavailability potential. Drug Deliv. 2011;18:599-612.

28. Beg S, Swain S, Singh HP, Patra CN, Rao MB. Development, optimization, and characterization of solid self-nanoemulsifying drug delivery systems of valsartan using porous carriers. AAPS PharmSciTech. 2012;13:1416-1427. 
29. Holm R, Tønsberg H, Jørgensen EB, Abedinpour P, Farsad S, Müllertz A. Influence of bile on the absorption of halofantrine from lipid-based formulations. Eur J Pharm Biopharm. 2012;81:281-287.

30. Moghimi SM, Moghimi M. Enhanced lymph node retention of subcutaneously injected IgG1-PEG2000-liposomes through pentameric $\mathrm{IgM}$ antibody-mediated vesicular aggregation. Biochim Biophys Acta. 2008;1778:51-55.

31. Ling R, Li Y, Yao Q, et al. Lymphatic chemotherapy induces apoptosis in lymph node metastases in a rabbit breast carcinoma model. J Drug Target. 2005; 13:137-142.

32. Frenkel V, Etherington A, Greene M, et al. Delivery of liposomal doxorubicin (Doxil) in a breast cancer tumor model: investigation of potential enhancement by pulsed-high intensity focused ultrasound exposure. Acad Radiol. 2006;13:469-479.

33. O'Brien ME, Wigler N, Inbar M, et al. Reduced cardiotoxicity and comparable efficacy in a phase III trial of pegylated liposomal doxorubicin $\mathrm{HCl}$ (Caelyx/Doxil) versus conventional doxorubicin for first-line treatment of metastatic breast cancer. Ann Oncol. 2004;15: 440-449.

34. Ling SS, Magosso E, Khan NA, Yuen KH, Barker SA. Enhanced oral bioavailability and intestinal lymphatic transport of a hydrophilic drug using liposomes. Drug Dev Ind Pharm. 2006;32:335-345.

35. Lawson KA, Anderson K, Snyder RM, et al. Novel vitamin E analogue and 9-nitro-camptothecin administered as liposome aerosols decrease syngeneic mouse mammary tumor burden and inhibit metastasis. Cancer Chemother Pharmacol. 2004;54:421-431.

36. Latimer P, Menchaca M, Snyder RM, et al. Aerosol delivery of liposomal formulated paclitaxel and vitamin E analog reduces murine mammary tumor burden and metastases. Exp Biol Med (Maywood). 2009;234:1244-1252.

37. Kojima N, Biao L, Nakayama T, Ishii M, Ikehara Y, Tsujimura K. Oligomannosecoated liposomes as a therapeutic antigen-delivery and an adjuvant vehicle for induction of in vivo tumor immunity. $J$ Control Release. 2008;129:26-32.

38. Harivardhan RL, Sharma RK, Chuttani K, Mishra AK, Murthy RS. Influence of administration route on tumor uptake and biodistribution of etoposide loaded solid lipid nanoparticles in Dalton's lymphoma tumor bearing mice. J Control Release. 2005;105:185-198.

39. Paliwal R, Rai S, Vaidya B, et al. Effect of lipid core material on characteristics of solid lipid nanoparticles designed for oral lymphatic delivery. Nanomedicine. 2009;5:184-191.

40. Zara GP, Bargoni A, Cavalli R, Fundarò A, Vighetto D, Gasco MR. Pharmacokinetics and tissue distribution of idarubicin-loaded solid lipid nanoparticles after duodenal administration to rats. $J$ Pharm Sci. 2002;91:1324-1333.

41. Cavalli R, Zara GP, Caputo O, Bargoni A, Fundarò A, Gasco MR. Transmucosal transport of tobramycin incorporated in SLN after duodenal administration to rats. Part I - a pharmacokinetic study. Pharmacol Res. 2000;42:541-545.

42. Cavalli R, Bargoni A, Podio V, Muntoni E, Zara GP, Gasco MR. Duodenal administration of solid lipid nanoparticles loaded with different percentages of tobramycin. J Pharm Sci. 2003;92:1085-1094.

43. Chalikwar SS, Belgamwar VS, Talele VR, Surana SJ, Patil MU. Formulation and evaluation of nimodipine-loaded solid lipid nanoparticles delivered via lymphatic transport system. Colloids Surf B Biointerfaces. 2012;97:109-116.

44. Muchow M, Maincent P, Müller RH, Keck CM. Production and characterization of testosterone undecanoate-loaded NLC for oral bioavailability enhancement. Drug Dev Ind Pharm. 2011;37:8-14.

45. Zhuang CY, Li N, Wang M, et al. Preparation and characterization of vinpocetine loaded nanostructured lipid carriers (NLC) for improved oral bioavailability. Int J Pharm. 2010;394:179-185.

46. Zhou L, Chen Y, Zhang Z, He J, Du M, Wu Q. Preparation of tripterine nanostructured lipid carriers and their absorption in rat intestine. Pharmazie. 2012;67:304-310.

47. Takakura Y, Matsumoto S, Hashida M, Sezaki H. Enhanced lymphatic delivery of mitomycin C conjugated with dextran. Cancer Res. 1984;44: $2505-2510$.
48. Jeong YI, Kim ST, Jin SG, et al. Cisplatin-incorporated hyaluronic acid nanoparticles based on ion-complex formation. J Pharm Sci. 2008;97:1268-1276.

49. Cai S, Xie Y, Bagby TR, Cohen MS, Forrest ML. Intralymphatic chemotherapy using a hyaluronan-cisplatin conjugate. J Surg Res. 2008; 147:247-252.

50. Maincent $\mathrm{P}$, Thouvenot $\mathrm{P}$, Amicabile C, et al. Lymphatic targeting of polymeric nanoparticles after intraperitoneal administration in rats. Pharm Res. 1992;9:1534-1539.

51. Liggins RT, D'Amours S, Demetrick JS, Machan LS, Burt HM. Paclitaxel loaded poly(L-lactic acid) microspheres for the prevention of intraperitoneal carcinomatosis after a surgical repair and tumor cell spill. Biomaterials. 2000;21:1959-1969.

52. Lu H, Li B, Kang Y, et al. Paclitaxel nanoparticle inhibits growth of ovarian cancer xenografts and enhances lymphatic targeting. Cancer Chemother Pharmacol. 2007;59:175-181.

53. Liu J, Wong HL, Moselhy J, Bowen B, Wu XY, Johnston MR. Targeting colloidal particulates to thoracic lymph nodes. Lung Cancer. 2006;51:377-386.

54. Liu J, Meisner D, Kwong E, Wu XY, Johnston MR. A novel translymphatic drug delivery system: Implantable gelatin sponge impregnated with PLGA-paclitaxel microspheres. Biomaterials. 2007;28: 3236-3244.

55. McAllaster JD, Cohen MS. Role of the lymphatics in cancer metastasis and chemotherapy applications. Adv Drug Deliv Rev. 2011;63: $867-875$.

56. Nune SK, Gunda P, Majeti BK, Thallapally PK, Forrest ML. Advances in lymphatic imaging and drug delivery. Adv Drug Deliv Rev. 2011;63: 876-885.

57. Tran Cao HS, McElroy M, Kaushal S, Hoffman RM, Bouvet M. Imaging of the interaction of cancer cells and the lymphatic system. Adv Drug Deliv Rev. 2011;63:886-889.

58. Moghimi SM, Bonnemain B. Subcutaneous and intravenous delivery of diagnostic agents to the lymphatic system: applications in lymphoscintigraphy and indirect lymphography. Adv Drug Deliv Rev. 1999;37: 295-312.

59. Cohen MS, Forrest ML. Lymphatic drug delivery: therapy, imaging and nanotechnology. Preface. Adv Drug Deliv Rev. 2011;63:865-866.

60. Müller RH. Lipid nanoparticles: recent advances. Adv Drug Deliv Rev. 2007;59:375-376.

61. Müller RH, Radtke M, Wissing SA. Nanostructured lipid matrices for improved microencapsulation of drugs. Int J Pharm. 2002;242: 121-128.

62. Müller RH, Gohla S, Dingler A, Schneppe T. Large-scale production of solid-lipid nanoparticles (SLN) and nanosuspension. In: Wise DL, editor. Handbook of Pharmaceutical Controlled Release Technology. Basel, Switzerland: Marcel Dekker; 2000.

63. Uner M. Preparation, characterization and physico-chemical properties of solid lipid nanoparticles (SLN) and nanostructured lipid carriers (NLC): their benefits as colloidal drug carrier systems. Pharmazie. 2006;61:375-386.

64. Müller RH, Mäder K, Gohla S. Solid lipid nanoparticles (SLN) for controlled drug delivery - a review of the state of the art. Eur J Pharm Biopharm. 2000;50:161-177.

65. Wissing SA, Kayser O, Müller RH. Solid lipid nanoparticles for parenteral drug delivery. Adv Drug Deliv Rev. 2004;56:1257-1272.

66. Mehnert W, Mäder K. Solid lipid nanoparticles: production, characterization and applications. Adv Drug Deliv Rev. 2001;47: 165-196.

67. Yuan H, Chen J, Du YZ, Hu FQ, Zeng S, Zhao HL. Studies on oral absorption of stearic acid SLN by a novel fluorometric method. Colloids Surf B Biointerfaces. 2007;58:157-164.

68. Wong HL, Bendayan R, Rauth AM, Li Y, Wu XY. Chemotherapy with anticancer drugs encapsulated in solid lipid nanoparticles. Adv Drug Deliv Rev. 2007;59:491-504.

69. Cai S, Yang Q, Bagby TR, Forrest ML. Lymphatic drug delivery using engineered liposomes and solid lipid nanoparticles. Adv Drug Deliv Rev. 2011;63:901-908. 
70. Jain RK. Barriers to drug delivery in solid tumors. Sci Am. 1994;271: 58-65.

71. Videira MA, Botelho MF, Santos AC, Gouveia LF, de Lima JJ, Almeida AJ. Lymphatic uptake of pulmonary delivered radiolabelled solid lipid nanoparticles. J Drtablesug Target. 2002;10:607-613.

72. Videira M, Almeida AJ, Fabra A. Preclinical evaluation of a pulmonary delivered paclitaxel-loaded lipid nanocarrier antitumor effect. Nanomedicine. 2012;8:1208-1215.

73. Bargoni A, Cavalli R, Caputo O, Fundaro A, Gasco MR, Zara GP. Solid lipid nanoparticles in lymph and plasma after duodenal administration to rats. Pharm Res. 1998;15:745-750.

74. Haque AK. Pathology of carcinoma of lung: an update on current concepts. J Thorac Imaging. 1991;7:9-20.

75. Chen XQ, Stroun M, Magnenat JL. Microsatellite alterations in plasma DNA of small cell lung cancer patients. Nat Med. 1996;2: 1033-1035.

76. Clark R, Ihde DC. Small-cell lung cancer: treatment progress and prospects. Oncology. 1998;12:647-658.

77. Zangemeister-Wittke U, Stahel RA. Novel approaches to the treatment of small-cell lung cancer. Cell Mol Life Sci. 1999;55:1585-1598.

78. Langenback EG, Bergofsky EH, Halpern JG, Foster WM. Supramicronsized particle clearance from alveoli: route and kinetics. J Appl Physiol. 1990;69:1302-1308.

79. McIntire GL, Bacon ER, Toner JL, et al. Pulmonary delivery of nanoparticles of insoluble, iodinated CT X-ray contrast agents to lung draining lymph nodes in dogs. J Pharm Sci. 1998;87:1466-1470.

80. Choi SH, Jin SE, Lee MK, et al. Novel cationic solid lipid nanoparticles enhanced p53 gene transfer to lung cancer cells. Eur J Pharm Biopharm. 2008;68:545-554.

81. Müller RH, Radtke M, Wissing SA. Solid lipid nanoparticles (SLN) and nanostructured lipid carriers (NLC) in cosmetic and dermatological preparations. Adv Drug Deliv Rev. 2002;54:131-155.

82. Saupe A, Wissing SA, Lenk A, Schmidt C, Müller RH. Solid lipid nanoparticles (SLN) and nanostructured lipid carriers (NLC) - structural investigations on two different carrier systems. Biomed Mater Eng. 2005;15:393-402.

83. Jenning V, Thunemann AF, Gohla SH. Characterisation of a novel solid lipid nanoparticle carrier system based on binary mixtures of liquid and solid lipids. Int J Pharm. 2000;199:167-177.

84. Oussoren C, Storm G. Liposomes to target the lymphatics by subcutaneous administration. Adv Drug Deliv Rev. 2001;50:143-156.

85. Walker JE Jr, Odden AR, Jeyaseelan S, et al. Ethanol exposure impairs LPS-induced pulmonary LIX expression: alveolar epithelial cell dysfunction as a consequence of acute intoxication. Alcohol Clin Exp Res. 2009;33:357-365.

86. Jaques PA, Kim CS. Measurement of total lung deposition of inhaled ultrafine particles in healthy men and women. Inhal Toxicol. 2000;12:715-731.

87. Chambers AF, Groom AC, MacDonald IC. Dissemination and growth of cancer cells in metastatic sites. Nat Rev Cancer. 2002;2: 563-572.

88. O'Driscoll CM, Griffin BT. Biopharmaceutical challenges associated with drugs with low aqueous solubility - the potential impact of lipidbased formulations. Adv Drug Deliv Rev. 2008;60:617-624

89. Yang S, Zhu J, Lu Y, Liang B, Yang C. Body distribution of camptothecin solid lipid nanoparticles after oral administration. Pharm Res. 1999;16:751-757.

90. Jacobs C, Kayser O, Müller RH. Nanosuspensions as a new approach for the formulation for the poorly soluble drug tarazepide. Int $J$ Pharm. 2000;196:161-164.

91. Boyd M, Risovic V, Jull P, Choo E, Wasan KM. A stepwise surgical procedure to investigate the lymphatic transport of lipid-based oral drug formulations: cannulation of the mesenteric and thoracic lymph ducts within the rat. J Pharmacol Toxicol Methods. 2004;49:115-120.

92. Edwards GA, Porter CJ, Caliph SM, Khoo SM, Charman WN. Animal models for the study of intestinal lymphatic drug transport. Adv Drug Deliv Rev. 2001;50:45-60.
93. Onizuka M, Flatebø T, Nicolaysen G. Lymph flow pattern in the intact thoracic duct in sheep. $J$ Physiol.1997;503(Pt 1):223-234.

94. Segrave AM, Mager DE, Charman SA, Edwards GA, Porter CJ. Pharmacokinetics of recombinant human leukemia inhibitory factor in sheep. J Pharmacol Exp Ther. 2004;309:1085-1092.

95. White DG, Story MJ, Barnwell SG. An experimental model for studying the effects of a novel lymphatic drug delivery system for propranolol. Int J Pharm. 1991;69:169-174.

96. Bocci V, Muscettola M, Grasso G, Magyar Z, Naldini A, Szabo G. The lymphatic route. 1. Albumin and hyaluronidase modify the normal distribution of interferon in lymph and plasma. Experientia. 1986;42:432-433.

97. Khoo SM, Edwards GA, Porter CJ, Charman WN. A conscious dog model for assessing the absorption, enterocyte-based metabolism, and intestinal lymphatic transport of halofantrine. J Pharm Sci. 2001;90: 1599-1607.

98. Khoo SM, Shackleford DM, Porter CJ, Edwards GA, Charman WN Intestinal lymphatic transport of halofantrine occurs after oral administration of a unit-dose lipid-based formulation to fasted dogs. Pharm Res. 2003;20:1460-1465.

99. Lespine A, Chanoit G, Bousquet-Melou A, et al. Contribution of lymphatic transport to the systemic exposure of orally administered moxidectin in conscious lymph duct-cannulated dogs. Eur J Pharm Sci. 2006;27:37-43.

100. Kagan L, Gershkovich P, Mendelman A, Amsili S, Ezov N, Hoffman A. The role of the lymphatic system in subcutaneous absorption of macromolecules in the rat model. Eur J Pharm Biopharm. 2007;67: 759-765.

101. Dahan A, Hoffman A. Evaluation of a chylomicron flow blocking approach to investigate the intestinal lymphatic transport of lipophilic drugs. Eur J Pharm Sci. 2005;24:381-388.

102. Trevaskis NL, Charman WN, Porter CJ. Lipid-based delivery systems and intestinal lymphatic drug transport: a mechanistic update. Adv Drug Deliv Rev. 2008;60:702-716.

103. Yáñez JA, Wang SW, Knemeyer IW, Wirth MA, Alton KB. Intestinal lymphatic transport for drug delivery. Adv Drug Deliv Rev. 2011;63: 923-942.

104. O'Driscoll CM. Lipid-based formulations for intestinal lymphatic delivery. Eur J Pharm Sci. 2002;15:405-415.

105. Seeballuck F, Ashford MB, O’Driscoll CM. The effects of Pluronics block copolymers and Cremophor EL on intestinal lipoprotein processing and the potential link with P-glycoprotein in Caco-2 cells. Pharm Res. 2003;20:1085-1092.

106. Seeballuck F, Lawless E, Ashford MB, O’Driscoll CM. Stimulation of triglyceride-rich lipoprotein secretion by polysorbate 80 : in vitro and in vivo correlation using Caco-2 cells and a cannulated rat intestinal lymphatic model. Pharm Res. 2004;21:2320-2326.

107. Karpf DM, Holm R, Garafalo C, Levy E, Jacobsen J, Müllertz A. Effect of different surfactants in biorelevant medium on the secretion of a lipophilic compound in lipoproteins using Caco-2 cell culture. J Pharm Sci. 2006;95:45-55.

108. Gershkovich P, Hoffman A. Uptake of lipophilic drugs by plasma derived isolated chylomicrons: linear correlation with intestinal lymphatic bioavailability. Eur J Pharm Sci. 2005;26: 394-404.

109. Dahan A, Hoffman A. Rationalizing the selection of oral lipid based drug delivery systems by an in vitro dynamic lipolysis model for improved oral bioavailability of poorly water soluble drugs. J Control Release. 2008;129:1-10.

110. Holm R, Hoest J. Successful in silico predicting of intestinal lymphatic transfer. Int J Pharm. 2004;272:189-193.

111. Chen H, Langer R. Oral particulate delivery: status and future trends. Adv Drug Deliv Rev. 1998;34:339-350.

112. Simon L. Special section on oral particulate absorption. J Drug Target. 1995;3:51-51.

113. Porter CJ, Charman WN. Intestinal lymphatic drug transport: an update. Adv Drug Deliv Rev. 2001;50:61-80. 
114. Luo G, Yu X, Jin C, et al. LyP-1-conjugated nanoparticles for targeting drug delivery to lymphatic metastatic tumors. Int $J$ Pharm. 2010;385:150-156.

115. Oussoren C, Zuidema J, Crommelin DJ, Storm G. Lymphatic uptake and biodistribution of liposomes after subcutaneous injection. II. Influence of liposomal size, lipid compostion and lipid dose. Biochim Biophys Acta. 1997;1328:261-272.

116. Kaminskas LM, Porter CJ. Targeting the lymphatics using dendritic polymers (dendrimers). Adv Drug Deliv Rev. 2011;63:890-900.

117. Patel HM, Boodle KM, Vaughan-Jones R. Assessment of the potential uses of liposomes for lymphoscintigraphy and lymphatic drug delivery. Failure of 99m-technetium marker to represent intact liposomes in lymph nodes. Biochim Biophys Acta. 1984;801:76-86.

118. Rao DA, Forrest ML, Alani AW, Kwon GS, Robinson JR. Biodegradable PLGA based nanoparticles for sustained regional lymphatic drug delivery. J Pharm Sci. 2010;99:2018-2031.

119. Takakura Y, Atsumi R, Hashida M, Sezaki H. Development of a novel polymeric prodrug of mitomycin $\mathrm{C}$, mitomycin $\mathrm{C}$-dextran conjugate with anionic charge. II. Disposition and pharmacokinetics following intravenous and intramuscular administration. Int J Pharm. 1987;37: $145-154$
120. Takakura Y, Hashida M, Sezaki H. Anatomy and physiology of the lymphatics. In: Charman WN, Stella VJ, editors. Lymphatic Transport of Drugs. Boca Raton, FL: CRC Press Inc; 1992.

121. Porter CJ. Drug delivery to the lymphatic system. Crit Rev Ther Drug Carrier Syst. 1997;14:333-393.

122. Clogston JD, Patri AK. Zeta potential measurement. Methods Mol Biol. 2011;697:63-70.

123. Kaur CD, Nahar M, Jain NK. Lymphatic targeting of zidovudine using surface-engineered liposomes. J Drug Target. 2008;16:798-805.

124. Dahlbäck B, Hermansson M, Kjelleberg S, Norkrans B. The hydrophobicity of bacteria - an important factor in their initial adhesion at the air-water interface. Arch Microbiol. 1981;128:267-270.

125. Patel HM. Serum opsonins and liposomes: their interaction and opsonophagocytosis. Crit Rev Ther Drug Carrier Syst. 1992;9:39-90.

126. Charman WN, Stella VJ. Estimating the maximum potential for intestinal lymphatic transport of lipophilic drug molecules. Int $J$ Pharm. 1986;34:175-178.

127. Sanjula B, Shah FM, Javed A, Alka A. Effect of poloxamer 188 on lymphatic uptake of carvedilol-loaded solid lipid nanoparticles for bioavailability enhancement. J Drug Target. 2009;17:249-256.
International Journal of Nanomedicine

\section{Publish your work in this journal}

The International Journal of Nanomedicine is an international, peerreviewed journal focusing on the application of nanotechnology in diagnostics, therapeutics, and drug delivery systems throughout the biomedical field. This journal is indexed on PubMed Central, MedLine, CAS, SciSearch ${ }^{\circledR}$, Current Contents ${ }^{\circledR} /$ Clinical Medicine,

\section{Dovepress}

Journal Citation Reports/Science Edition, EMBase, Scopus and the Elsevier Bibliographic databases. The manuscript management system is completely online and includes a very quick and fair peer-review system, which is all easy to use. Visit http://www.dovepress.com/ testimonials.php to read real quotes from published authors. 